\title{
Does Maxillary Sinus have any Influence on the Skeletal Class or Facial Type?
}

\section{Hiba Gmati ${ }^{1 *}$, Mariem Nasfi ${ }^{1}$, Mounira Rtibi ${ }^{1}$, Ines Methioub ${ }^{1}$, Anissa El Yemni Zinelabidine ${ }^{2}$ and Abdellatif Boughzela ${ }^{2}$}

${ }^{1}$ Resident in Orthodontics, Department of Dentistry, Farhat Hached Hospital, Sousse, Tunisia

${ }^{2}$ Professor in Orthodontics, Department of Dentistry, Farhat Hached Hospital,

Sousse, Tunisia

*Corresponding Author: Hiba Gmati, Resident in Orthodontics, Department of Dentistry, Farhat Hached Hospital, Sousse, Tunisia.
Received: June 24, 2021

Published: July 19, 2021

(C) All rights are reserved by Hiba Gmati., et

al.

\section{Abstract}

Introduction: Maxillary sinuses are very important cavities of the face. Their relationship with some teeth allows to suggest that maxillary sinus development may affect skeletal malocclusions and vertical facial types.

Aim: To determine the relationship between maxillary sinus size, vertical facial types, and different skeletal classes for both genders in a Tunisian population.

Materials and Methods: A retrospective study on 60 lateral cephalograms of Tunisian males and females aged between 12 and 29 years was performed. They were classified into three groups based on ANB, FMA, and GOGN-SN angles.

Five measurements were used to assess the maxillary sinus size: two linear and three areas. They were calculated manually in all the radiographs. ANOVA test was used to determine the relationship between the different measurements.

Results: All measurements were found to be greater in males than in females. No significant association was observed for both skeletal classes and facial types.

Conclusion: No relation was observed between maxillary sinus size, skeletal classes and facial types.

Keywords: Lateral Cephalograms; Maxillary Sinus; Skeletal Classes; Vertical Facial Types

\section{Introduction}

The maxillary sinus is the largest of the four paranasal maxillary sinuses [7]. It is a cavity or a space filled with air in the body of the maxilla [13]. It begins to develop at about 12 weeks of fetal life, arising by lateral invagination of the mucous membrane of the middle nasal meatus, forming a slit-like space. Development of the maxillary sinus begins at the ethmoidal infundibulum in the third month of fetal life [16]. After birth, it continues to extend both laterally and inferiorly. It expands not only downwards but also forwards and backwards from its original invagination during the rapid growth period, from birth to three years of age and from seven to twelve years of age [9]. The Floor of the maxillary sinus is formed by the alveolar process of the maxilla and it shares a close anatomic and functional relationship with posterior maxillary teeth [14]. It is related to the teeth roots in variable degrees; either between the roots of adjacent teeth and the roots of the same tooth or elevated in spots to accommodate the roots apices and the roots occasionally protruding into the maxillary sinus cavity. This close relationship allows us to suggest that maxillary sinus development might affect skeletal malocclusions and vertical facial types. 


\section{Purpose of the Study}

The purpose of this study was to investigate on lateral cephalograms the relationship between maxillary sinus size, vertical facial types and different skeletal classes for both genders in a Tunisian population.

\section{Materials and Methods}

The sample of the study was collected from patients who presented to the Department of Orthodontics at Farhat Hached University Hospital in Sousse. Sixty Tunisian patients were included. The inclusion criteria were as follows: Tunisian origin, age range between 12 and 29 years, no history of abnormal habits (mouth breathing), no apparent facial disharmony or cleft lip and palate, no history of orthodontic, facial, orthopedic or surgical treatment, having fully-erupted permanent dentition with the exception of third molars, presenting no tooth decay, no missing teeth, no asymmetrical faces, having no associated syndromes and no maxillary sinus pathology.

Lateral standardized cephalograms were taken by a single operator using the same X-ray device.

\section{Cephalometric analysis}

Lateral cephalograms of the involved subjects were traced and measured by a single investigator.

Definitions of the cephalometric points used in the measurement:

1. S (Sella): The mid point of the hypophysial fossa.

2. $\mathrm{N}$ (Nasion): The most anterior point on the naso-frontal suture in the median plane.

3. A (sub spinal): The deepest midline point on the premaxilla between the anterior nasal spine and the prosthion.

4. B (Supra mental): The deepest midline point on the mandible between the infra dental and the Pogonion.

5. ANS (Anterior nasal spine): It is the tip of the bony anterior nasal spine in the median plane.

6. PNS (Posterior nasal spine): It is a constructed radiological point: The intersection of a continuation of the anterior wall of the pterygo-palatin fossa and the floor of the nose. It marks the dorsal limit of the maxilla.

7. An: The most anterior point of the maxillary sinus.
8. $\mathrm{An}^{\prime}$ : The orthogonal projection of A to the $\mathrm{x}$-axis.

9. Po: The most posterior point of the maxillary sinus.

10. Po: The orthogonal projection of Po onto the $\mathrm{x}$ - axis.

11. Su: the most superior point of the maxillary sinus.

12. $\mathrm{Su}^{\prime}:$ the orthogonal projection of $\mathrm{Su}$ onto the $\mathrm{y}$-axis.

13. In: The most inferior point of the maxillary sinus.

14. In': the orthogonal projection of In into the $y$-axis $[6,8,15]$.

Definitions of the cephalometric planes used in the measurement:

1. The S-N plane (Sella-Nasion): It is the anterior posterior extent of the anterior cranial base [15].

2. The Frankfort horizontal plane (FH): It is a horizontal plane running between the portion and the orbital [15].

3. The palatal plane or the Maxillary plane (Max. P.): The line joining ANS and PNS [15].

4. N-A line: Formed by a line joining the Nasion and point $\mathrm{A}$ [12].

5. N-B line: Formed by a line joining the Nasion and point B [12].

6. x-axis: Horizontal plane, parallel to the Frankfort plane passing through the Sella.

7. y-axis: Vertical plane, perpendicular to the Frankfort plane passing through the Sella.

\section{Method of measurement}

The linear and area measurements of the maxillary sinuses were performed using the method of Toshiya., et al [8]:

1. Maxillary sinus length (M.S.L) (mm): This line extends from An- to Po-

2. Maxillary sinus height (M.S.H) (mm): This line extends from Su- to In-

3. Upper maxillary sinus area (UMSA) $\left(\mathrm{mm}^{2}\right)$ : It is defined by the surface of the maxillary sinus portion above the maxillary plane, extending horizontally from the anterior nasal spine (ANS)to the posterior nasal spine (PNS).

4. Lower maxillary sinus area (LMSA) $\left(\mathrm{mm}^{2}\right)$ : It represents the lower area of the Maxillary sinus below the palatal plane. 
5. Total maxillary sinus area (TMSA) $\left(\mathrm{mm}^{2}\right)$ : It represents the summation of the upper and lower maxillary sinus areas using standard cephalometric reference points, planes, variables and measurements (Figure 1) according to Kwak., et al. [12].

The reference points, planes and variables used are shown in figure 1.

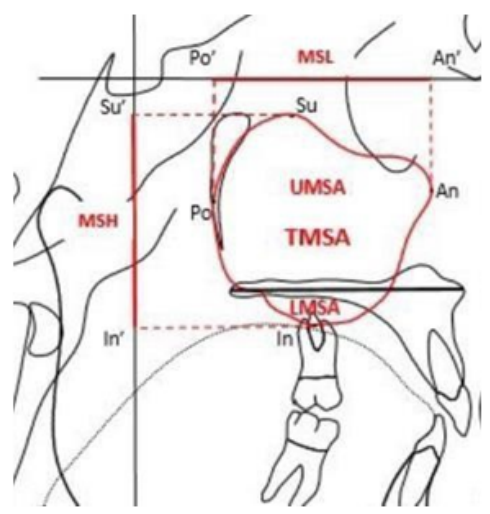

Figure 1: Cephalometric landmarks, planes and variables [12].

Then, the sample was divided into three groups based on the ANB angle:

1. ANB angle between 0 - 4 degrees (skeletal class I).

2. ANB greater than 4 degrees (skeletal class II).

3. ANB less than 0 degrees (skeletal class III).

It was also divided into 3 groups on the basis of the FMA and GOGN SN angles:

1. FMA angle between 25 - 30 degrees and GoGn/Sn angle between 32 - 37 degrees (normodivergent/mesocephalic).

2. FMA angle greater than 30 degrees and GoGn/Sn greater than 37 degrees (hyperdivergent/dolichocephalic).

3. FMA angle less than 25 degrees and GoGn/Sn less than 32 degrees (hypodivergent/brachycephalic).

\section{Statistical analysis}

All statistical analyses were performed with SPSS 22.0 software.
Chi-square test was used to assess the differences between the maxillary sinus size measurements depending on gender. Oneway ANOVA test was used to assess the association significance between the maxillary sinus size measurements, three malocclusion groups and three facial biotype groups in the male, female and merged samples.

In the statistical evaluation, the following levels of significance were used: $\mathrm{P}>0.05$ Non-significant; $0.05 \geq \mathrm{P}>0.01 *$ Significant; $0.01 \geq \mathrm{P}>0.001^{* *}$ Highly significant; $\mathrm{P} \leq 0.001^{* * *}$ Very highly significant.

\section{Results}

The sample involved 21 male subjects and 39 female subjects (Figure 2).

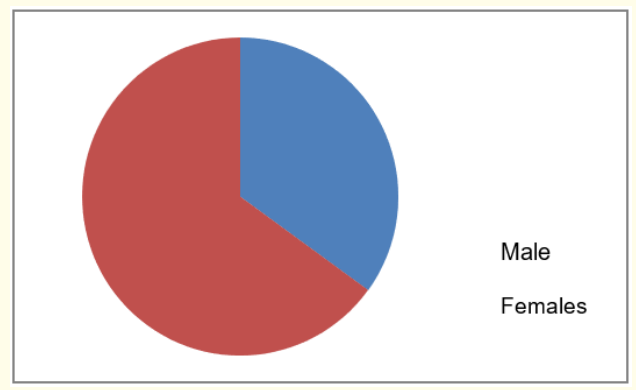

Figure 2: Distribution of the sample according to gender.

The mean age was 16 years (yrs) 8 months (mths) for male subjects and 16 years 9 months for female subjects (Table 1).

\begin{tabular}{|l|c|c|}
\hline Sex & Mean age & SD \\
\hline Males & 16yrs 8mths & 4.1 \\
\hline Females & 16yrs 9mths & 3.7 \\
\hline
\end{tabular}

Table 1: Mean age of the sample.

Results depending on the skeletal class

\begin{tabular}{|l|c|c|c|}
\hline Skeletal class & Males & Females & Total \\
\hline Cl I & 7 & 15 & 22 \\
\hline Cl II & 10 & 19 & 29 \\
\hline Cl III & 4 & 5 & 9 \\
\hline Total & 21 & 39 & 60 \\
\hline
\end{tabular}

Table 2: Distribution of the sample according to the skeletal class. 
Statistical analysis showed the following mean values for:

Maxillary sinus height

\begin{tabular}{|l|c|c|}
\hline Skeletal class & Males (mm) & Females (mm) \\
\hline Cl I & 40.714 & 41.8 \\
\hline Cl II & 44 & 41.052 \\
\hline Cl III & 47.5 & 40 \\
\hline
\end{tabular}

Maxillary sinus width

\begin{tabular}{|l|c|c|}
\hline Skeletal class & Males (mm) & Females (mm) \\
\hline Cl I & 46 & 43,466 \\
\hline Cl II & 45.2 & 43.21 \\
\hline Cl III & 42.5 & 43.2 \\
\hline
\end{tabular}

Maxillary sinus upper area

\begin{tabular}{|l|c|c|}
\hline Skeletal class & Males $\mathbf{( m m}^{\mathbf{2}} \mathbf{)}$ & Females $\mathbf{( m m}^{\mathbf{}} \mathbf{)}$ \\
\hline Cl I & 1559.266 & 1523.857 \\
\hline Cl II & 1537.8 & 1519.789 \\
\hline CIII & 1736.25 & 1452.4 \\
\hline
\end{tabular}

Maxillary sinus lower area

\begin{tabular}{|l|c|c|}
\hline Skeletal class & Males $\left(\mathbf{m m}^{\mathbf{}} \mathbf{)}\right.$ & Females $\left(\mathbf{m m}^{\mathbf{}} \mathbf{)}\right.$ \\
\hline Cl I & 196 & 126.266 \\
\hline Cl II & 248 & 145.263 \\
\hline CIII & 93 & 138.4 \\
\hline
\end{tabular}

Maxillary sinus total area

\begin{tabular}{|l|c|c|}
\hline Skeletal class & Males $\left(\mathbf{m m}^{\mathbf{2}}\right)$ & Females $\left(\mathbf{m m}^{2} \mathbf{)}\right.$ \\
\hline $\mathrm{Cl} \mathrm{I}$ & 1881.486 & 3113.54 \\
\hline $\mathrm{Cl} \mathrm{II}$ & 2000.8 & 1796.263 \\
\hline $\mathrm{CIII}$ & 2015.75 & 1741.8 \\
\hline
\end{tabular}

The mean maxillary height was found to be highest in the skeletal class III group and the skeletal class I group in the male and female samples, respectively.

The mean maxillary width was found to be highest in the skeletal class I group in the male, female and overall samples.

The upper maxillary sinus area was found to be greatest in the skeletal class III group and in the skeletal class I group in the male sample, and the female and overall samples, respectively.

The lower maxillary sinus area was found to be maximal in the skeletal class I group and the skeletal class III group in the male population and the female sample, respectively.

The total maxillary sinus area was found to be maximal in the skeletal class III group, the skeletal class I group, and the skeletal class II group in the male, female, and overall samples, respectively.

All these observations were statistically non-significant using one-way ANOVA test (Table 3-5).

\begin{tabular}{|l|c|c|c|c|c|c|c|}
\hline Parameter & Class I & SD & Class II & SD & Class III & SD & Anova test (p-value) \\
\hline MSH $(\mathrm{mm})$ & 40.7143 & 3.77334 & 44 & 5.05525 & 47.5 & 8.2664 & 0.153 \\
\hline MSL $(\mathrm{mm})$ & 46 & 3.95811 & 45.2 & 3.08401 & 42.5 & 4.20317 & 0.310 \\
\hline UMSA $\left(\mathrm{mm}^{2}\right)$ & 1523.8571 & 224.18031 & 1537.8 & 184.99117 & 1736.25 & 436.07367 & 0.189 \\
\hline LMSA $\left(\mathrm{mm}^{2}\right)$ & 196 & 156.10680 & 248 & 139.5638 & 93 & 82.01626 & 0.375 \\
\hline TMSA $\left(\mathrm{mm}^{2}\right)$ & 1881.4286 & 311.35342 & 2000.80 & 344.11490 & 2015.75 & 371.91968 & 0.734 \\
\hline
\end{tabular}

Table 3: Descriptive statistics and ANOVA for males.

\begin{tabular}{|l|c|c|c|c|c|c|c|}
\hline Parameter & Class I & SD & Class II & SD & Class III & SD & Anova Test (p- value) \\
\hline MSH $(\mathrm{mm})$ & 41.8 & 4.12657 & 41.0526 & 7.49425 & 40 & 4.74342 & 0.840 \\
\hline MSL $(\mathrm{mm})$ & 43.4667 & 3.02056 & 43.2105 & 4.32793 & 43.2 & 3.89872 & 0.979 \\
\hline UMSA $\left(\mathrm{mm}^{2}\right)$ & 1559.2667 & 193.59769 & 1519.7895 & 391.83976 & 1452.4000 & 257.93080 & 0.8 \\
\hline LMSA $\left(\mathrm{mm}^{2}\right)$ & 126.2667 & 78.59523 & 145.2632 & 99.96046 & 138.4000 & 50.54503 & 0.822 \\
\hline TMSA $\left(\mathrm{mm}^{2}\right)$ & 1812.0000 & 173.20384 & 1796.2632 & 476.89748 & 1741.8000 & 338.61955 & 0.935 \\
\hline
\end{tabular}

Table 4: Descriptive statistics and ANOVA for females. 
Does Maxillary Sinus have any Influence on the Skeletal Class or Facial Type?

\begin{tabular}{|l|c|c|c|c|c|c|c|}
\hline Parameter & Class I & SD & Class II & S D & Class III & SD & Anova test p-value \\
\hline MSH $(\mathrm{mm})$ & 41.4545 & 3.96085 & 42.0690 & 6.80825 & 43.3333 & 7.24569 & 0.731 \\
\hline MSL (mm) & 44.2727 & 3.46660 & 43.8966 & 4.00308 & 42.8889 & 3.78961 & 0.654 \\
\hline UMSA (mm $\left.{ }^{2}\right)$ & 1578.5556 & 199.07476 & 1526 & 331.32914 & 1548 & 356.30749 & 0.890 \\
\hline LMSA $\left(\mathrm{mm}^{2}\right)$ & 148.4545 & 110.3901 & 180.8621 & 123.19953 & 118.2222 & 66.12446 & 0.293 \\
\hline TMSA $\left(\mathrm{mm}^{2}\right)$ & 1834.0909 & 220.8906 & 1866.7931 & 440.5188 & 1863.5556 & 360.6245 & 0.942 \\
\hline
\end{tabular}

Table 5: Descriptive statistics and ANOVA for the overall sample.

Results depending on facial biotypes

\begin{tabular}{|l|c|c|c|}
\hline Facial type & Males & Females & Total \\
\hline Hypodivergent & 4 & 4 & 8 \\
\hline Normodivergent & 6 & 15 & 21 \\
\hline Hyperdivergent & 11 & 20 & 31 \\
\hline Total & 21 & 39 & 60 \\
\hline
\end{tabular}

Table 6: Distribution according to facial types.

Statistical analysis showed the following mean values for:

Maxillary sinus height

\begin{tabular}{|l|c|c|}
\hline Facial type & Males (mm) & Females (mm) \\
\hline Hypodivergent & 43.5 & 39 \\
\hline Normodivergent & 39.333 & 41.533 \\
\hline Hyperdivergent & 45.909 & 41.285 \\
\hline
\end{tabular}

Maxillary sinus length

\begin{tabular}{|l|c|c|}
\hline Facial type & Males (mm) & Females (mm) \\
\hline Hypodivergent & 46.25 & 42.33 \\
\hline Normodivergent & 43.5 & 44.33 \\
\hline Hyperdivergent & 45.27 & 42.71 \\
\hline
\end{tabular}

Upper maxillary sinus area

\begin{tabular}{|l|c|c|}
\hline Facial type & Males $\left(\mathbf{m m}^{\mathbf{}} \mathbf{)}\right.$ & Females $\left(\mathbf{m m}^{\mathbf{}} \mathbf{)}\right.$ \\
\hline Hypodivergent & 1631.75 & 1462.66 \\
\hline Normodivergent & 1417.166 & 1573.66 \\
\hline Hyperdivergent & 1736.25 & 1452.4 \\
\hline
\end{tabular}

Maxillary sinus lower area

\begin{tabular}{|l|c|c|}
\hline Facial type & Males $\left(\mathbf{m m}^{\mathbf{2}} \mathbf{)}\right.$ & Females $\left(\mathbf{m m}^{\mathbf{2}} \mathbf{)}\right.$ \\
\hline Hypodivergent & 172.5 & 65.33 \\
\hline Normodivergent & 177.166 & 127.06 \\
\hline Hyperdivergent & 225.09 & 154.47 \\
\hline
\end{tabular}

Maxillary sinus total area

\begin{tabular}{|l|c|c|}
\hline Facial type & Males $\mathbf{( m m}^{\mathbf{}} \mathbf{)}$ & Females $\left(\mathbf{m m}^{\mathbf{}} \mathbf{)}\right.$ \\
\hline Hypodivergent & 2021.5 & 1645.66 \\
\hline Normodivergent & 1723 & 1839 \\
\hline Hyperdivergent & 2074.27 & $1784.95 \mathrm{~mm}^{2}$ \\
\hline
\end{tabular}

The mean maxillary sinus width was found to be highest in the hypodivergent male group, the overall samples, as well as the normodivergent female group.

The mean maxillary height was found to be highest in the hyperdivergent group and the normodivergent group in the male and the overall samples and the female sample, respectively.

The upper maxillary sinus area was found to be greatest in the hyperdivergent group in the male and the female samples.

The lower maxillary sinus area was found to be maximal in the hyperdivergent group in the male, female and overall samples.

The total maxillary sinus area was found to be maxim al in the hyperdivergent and the normodivergent groups in the male and the overall samples, and the female sample, respectively.

All these observations were statistically non-significant using one-way ANOVA test (Table 7-9). 


\begin{tabular}{|l|c|c|c|c|c|c|c|}
\hline & Normo & SD & Hypo & SD & Hyper & SD & ANOVA \\
\hline MSH & 39.333 & 4.589 & 43.5 & 3.316 & 45.909 & 5.787 & 0.065 \\
\hline MSL & 43.5 & 4.183 & 46.25 & 4.193 & 45.272 & 2.337 & 0.484 \\
\hline UMSA & 141.7166 & 223.714 & 1631.75 & 218.471 & 1632727 & 269.023 & 0.229 \\
\hline LMSA & 177.166 & 134.316 & 172.5 & 131.071 & 225.0909 & 160.095 & 0.748 \\
\hline TMSA & 1723 & 345.076 & 2021.5 & 330.306 & 2074.272 & 267.612 & 0.093 \\
\hline
\end{tabular}

Table 7: Descriptive statistics and ANOVA for males.

\begin{tabular}{|l|c|c|c|c|c|c|c|}
\hline & Normo & SD & Hypo & SD & Hyper & SD & ANOVA \\
\hline MSH & 41.533 & 3.226 & 39 & 4 & 41.2857 & 7.6101 & 0.803 \\
\hline MSL & 44.333 & 2.636 & 42.333 & 2.081 & 42.714 & 4.440 & 0.401 \\
\hline UMSA & 1573.666 & 166.242 & 1462.666 & 124.343 & 1501.619 & 395.0722 & 0.744 \\
\hline LMSA & 127.066 & 61.272 & 65.333 & 32.578 & 330 & 154.476 & 0.209 \\
\hline TMSA & 1839.8 & 162.334 & 1645.666 & 94.001 & 1784.952 & 474.615 & 0.697 \\
\hline
\end{tabular}

Table 8: Descriptive statistics and ANOVA for females.

\begin{tabular}{|l|c|c|c|c|c|c|c|}
\hline & Normo & SD & Hypo & SD & Hyper & SD & ANOVA \\
\hline MSH & 40.9048 & 3.686 & 41.5714 & 4.0766 & 42.8750 & 7.29 & 0.492 \\
\hline MSL & 44.0952 & 3.0643 & 44.5714 & 3.823 & 43.5938 & 4.195 & 0.787 \\
\hline UMSA & 1528.9524 & 192.741 & 1559.2857 & 192.839 & 1546.6875 & 357.836 & 0.964 \\
\hline LMSA & 141.3810 & 87.613 & 126.5714 & 110.566 & 178.7500 & 126.224 & 0.360 \\
\hline TMSA & 1806.4286 & 226.140 & 1860.4286 & 312.816 & 1884.4063 & 433.5 & 0.744 \\
\hline
\end{tabular}

Table 9: Descriptive statistics and ANOVA for the overall sample.

The Chi-square test showed no significant differences between the two genders with regard to all the measurements. However, all the mean values of the maxillary sinus length, height and areas were higher in males than in females for all the skeletal classes and facial biotypes (Table 10).

\begin{tabular}{|l|c|c|c|c|c|}
\hline & MSL & MSH & UMSA & LMSA & TMSA \\
\hline Females & 43.3077 & 41.2051 & 1526.3333 & 137.0769 & 1795.3333 \\
\hline Males & 44.9524 & 43.5714 & 1570.9524 & 208.9500 & 1963.8571 \\
\hline Chi square test & 0.736 & 0.453 & 0.621 & 0.415 & 0.499 \\
\hline
\end{tabular}

Table 10: Variation of maxillary sinus dimensions according to gender.

\section{Discussion}

No significant differences between genders, skeletal classes or facial types were found with regard to Maxillary sinus size.

All the measurements determining maxillary sinus size were found to be greater in males than in females, which is in line with the results of other authors $[8,10,11,14]$. However, some studies have reported a significant difference between the two genders $[3,4,7]$.

The upper and lower maxillary sinus areas were found to be greater in the skeletal class I group than in the skeletal class III group in the overall sample. 
The total maxillary sinus area was found to be greater in the skeletal class II group in the overall sample.

Hyperdivergent subjects were found to have greater maxillary sinus dimensions.

Although these differences were not statistically significant, they could be explained by the fact that the maxillary sinus is located in different positions of the maxilla body.

Alberti reported that a small and narrow maxillary sinus with a concave anterior wall gives rise to a dish face, and that a large maxillary sinus with a convex anterior wall gives rise to a rounded face [2].

\section{Study Limitations}

Lateral cephalograms are routinely used in orthodontic practice. They permit total visualization of the maxillary sinus. However, they are limited to only two dimensions, leaving the horizontal dimension unexplored. To overcome this limitation, computed tomography, which is a very advantageous imaging, is used.

The patients' age, which is an important factor influencing maxillary sinus dimensions, was not considered in our study.

\section{Conclusion}

To summarize, no significant association was found between maxillary sinus size and skeletal classes, or facial biotypes.

Our results may be useful when mini implants for anchorage is included in orthodontic treatment to avoid maxillary sinus perforation, or in case of orthognathic surgeries to prevent alteration of the maxillary sinus when its contour is within the cutting limit.

\section{Bibliography}

1. Al-Azzawi AM. "Maxillary sinus Area in both Gender and its Relation to Skeletal Class III Malocclusion". Medical Journal of Babylon 10.2 (2013): 508-516.

2. Alberti PW. "Applied surgical anatomy of the maxillary sinus". Otolaryngologic Clinics of North America 9 (1976): 3-20.

3. Ariji Y., et al. "Age changes in the volume of the human maxillary sinus: a study using computed tomography". Dentomaxillofacial Radiology 23 (1994): 163-168.

4. Ayman H Urabi. "Digital lateral cephalometric assessment of maxillary sinus dimensions in different skeletal classes". Journal of Baghdad College of Dentistry 4.1 (2012): 35-38.
5. Daraze A. "Maxillary sinus size in different gender and sagittal skeletal classes: orthodontics and forensic interests". Orthodontics 2.1 (2016).

6. Downs W B. "Variations in facial relationship: their significance in treatment and prognosis". American Journal of Orthodontics 34.10 (1948): 812-840.

7. Emirzeoglu M., et al. "Volumetric evaluation of the paranasal maxillary sinuses in normal subjects using computer tomography images: a stereological study". Auris Nasus Larynx 34 (2007): 191-195.

8. Endo T., et al. "Cephalometric evaluation of maxillary sinus sizes in different malocclusion classes". Odontology 98.1 (2010): 65-72.

9. Graney DO and Rice DH. "Anatomy". In: Cummings CW, Fredrickson JM, Harker LA, Krause CJ, Schuller DE, editors. Otolaryngology: head and neck surgery (2nded). St. Louis: Mosby Year Book (1993): 901-906.

10. Jalal FA. "Estimation of gender and age using spiral CT scanning of maxillary sinuses and foramen magnum [Thesis]. Baghdad: Departmentoforal and maxillofacial radiology 2008, college of dentistry university of Baghdad (2008).

11. Jun BC., et al. "The analysis of maxillary sinus aeration according to aging process; volume assessment by 3 -dimensional reconstruction by high- resolutional CT scanning". Otolaryngology-Head and Neck Surgery 132 (2005): 429-434.

12. Kwak HH., et al. "Topographic anatomy of the inferior wall of the maxillary sinus in Koreans". International Journal of Oral and Maxillofacial Surgery 33 (2004): 382-388.

13. Porter G., et al. "Paranasal maxillary sinus anatomy and function" (2002).

14. Qadir M and Mushtaq M. "Maxillary sinus size and malocclusion: Is there any relation?" International Journal of Applied Dental Sciences 3.4 (2017): 333-337.

15. Rakosi T. "An Atlas and manual of cephalometric radiology". London: Wolfe Medical Publications 26 (1982): 40-46.

16. Suzuki H., et al. "Rhinologic computed tomogram evaluation in patients with cleft lip and palate". Archives of Otolaryngology Head and Neck Surgery 125 (1999): 1000-1004.

\section{Volume 5 Issue 8 August 2021}

\section{(C) All rights are reserved by Hiba Gmati., et al.}

